\title{
Delayed and Incidental Diagnosis of Transverse Testicular Ectopia
}

\author{
Süleyman Cüneyt Karakuş ${ }^{1}$, Hüseyin Kılınçaslan², İdris Ertaşkın¹, Naim Koku'1, Hasan Deliağa ${ }^{3}$ \\ ${ }^{1}$ Department of Pediatric Surgery, Gaziantep Children Hospital, Gaziantep, Turkey \\ ${ }^{2}$ Department of Pediatric Surgery, Faculty of Medicine, Bezmialem Vakıf University, Istanbul, Turkey \\ ${ }^{3}$ Department of Pediatric Surgery, Servergazi State Hospital, Denizli, Turkey
}

\begin{abstract}
Transverse testicular ectopia is a rare malformation in which both testes are placed in the same inguinal region. Most of the patients are diagnosed incidentally during inguinal exploration. We here report three cases of transverse testicular ectopia and discuss the causes of delayed and incidental diagnosis of this infrequent malformation. Although the mean age at presentation was reported as 4 years, the mean age of our patients was 7.7 months. We detected the contralateral testis in the inguinal canal in all of our patients preoperatively. The most important diagnostic criteria are to be aware of this rare malformation and getting suspicious in patients with one side inguinal hernia and an empty hemiscrotum on the other side. It is essential to perform an ultrasound scan in patients with such a clinical presentation.
\end{abstract}

Key Words: Transverse testicular ectopia, nonpalpable testes, inguinal hernia, orchiopexy

\section{Introduction}

Transverse testicular ectopia (TTE) was first described by Von Cenhossek in1886 (1). It is defined as the existence of both testes in the same inguinal region with an intact ipsilateral blood supply, epididymis, and vas $(2,3)$. Most of the patients are diagnosed incidentally during inguinal exploration for hernia repair or for nonpalpable testes $(2,4)$. The mean age at presentation was reported as four years (5). We here report three more cases and discuss the causes of delayed and incidental diagnosis of this infrequent malformation.

\section{Case Reports}

\section{Case 1}

A 10-month-old boy was admitted with a symptomatic right inguinal hernia. The right testis was palpable normally in the hemiscrotum but the left testis was nonpalpable on clinical examination. Both testes were detected by ultrasound (US) scan on the right side; one in the inguinal canal and other in the ipsilateral hemiscrotum (Figure 1). During inguinal exploration, both testes were differentiated with their own blood supply, epididymis and vas. The left testis was placed in the left hemiscrotum through the scrotal septum after high ligation of the hernia sac.

\section{Case 2}

A 6-month-old boy was admitted with a symptomatic right inguinal hernia and a bilateral empty hemiscrotum. Physical examination and US scan revealed both testes in the right inguinal canal. During inguinal exploration, both testes were detected in the inguinal canal with their own blood supply, epididymis and vas (Figure 2). The same procedure was performed.

\section{Case 3}

A 7-month-old boy presented with a symptomatic right inguinal hernia and a contralateral nonpalpable testis. The right testis was normally located in the ipsilateral hemiscrotum and the left testis was palpated in the right inguinal canal. Ultrasound scan authenticated the left testis in the right inguinal region. The same procedure was performed (Figure 3).

Parents have been informed of the malignant potential of the ectopic testis and a subsequent abdominal ultrasonography did not show any anomalies of the urogenital system.

\section{Discussion}

TTE, also known as testicular pseudo-duplication, unilateral double testis or transverse aberrant testicular maldescent, is a very rare form of testicular ectopia (3). There are many theories attempting to explain the embryonic development of this anomaly, but there is no uniform agreement. Putative factors include the development of both testes from the same germinal ridge, early fusion of the developing Wolffian ducts, testicular adherence to Müllerian structures and the obstruction of the inguinal ring preventing testicular descent on the ipsilateral side. Besides, the important role of the gubernaculum in the process of testicular descent has been proven in experimental studies and the most accepted theory is the abnormal attachment of the gubernacular remnant (6). 


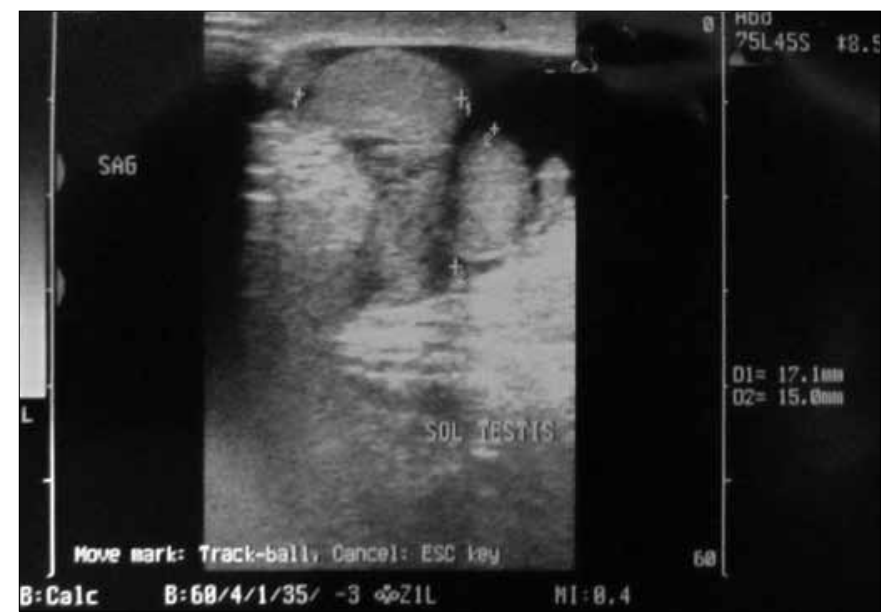

Figure 1. Ultrasound scan revealing one testis in the inguinal canal and the other in the ipsilateral hemiscrotum

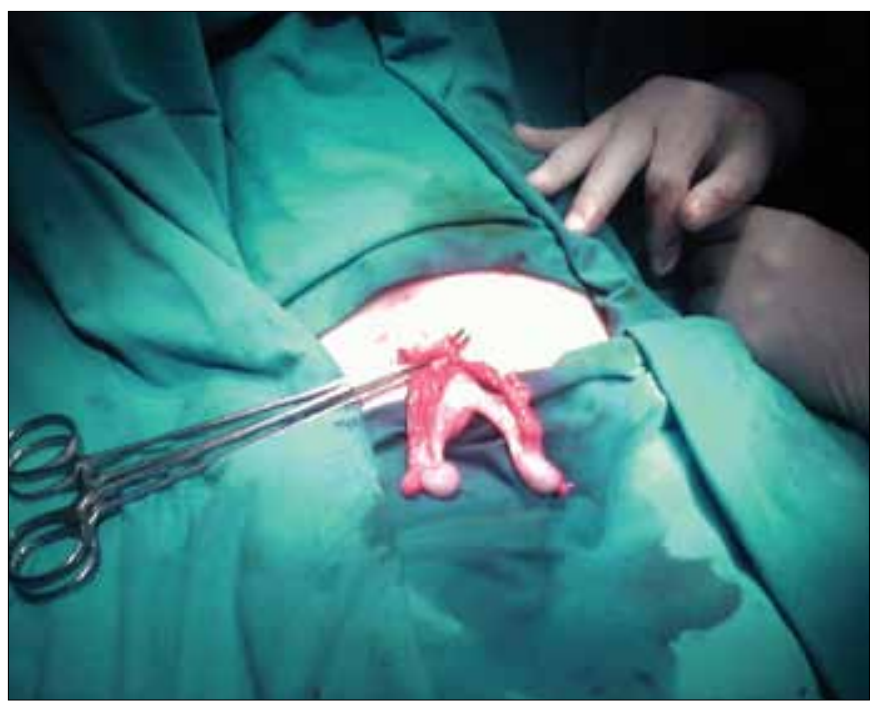

Figure 2. Intraoperative view showing both testes on the right side

A classification of this abnormality is defined according to the associated anomalies. In type I, TTE is associated with an inguinal hernia alone ( $40 \%$ to $50 \%$ ). Type II is associated with persistent or rudimentary Müllerian duct remnants (30\%) and type III is associated with disorders of genitourinary anomalies (hypospadias, scrotal abnormalities, and disorders of sex development) (20\%) (5). According to this classification, all our patients are type-I patients. The typical one side inguinal hernia with an empty contralateral hemiscrotum was present in all our cases (7). No other associated anomaly was detected.

Although the mean age at presentation was reported as 4 years, the mean age of our patients was 7.7 months (5). Since there are useful diagnostic modalities such as US scan, magnetic resonance imaging (MRI) and laparoscopy, most of the patients are still detected incidentally during exploration for inguinal hernia (7). An US scan may be helpful to detect the localization of the testes. We detected the contralateral

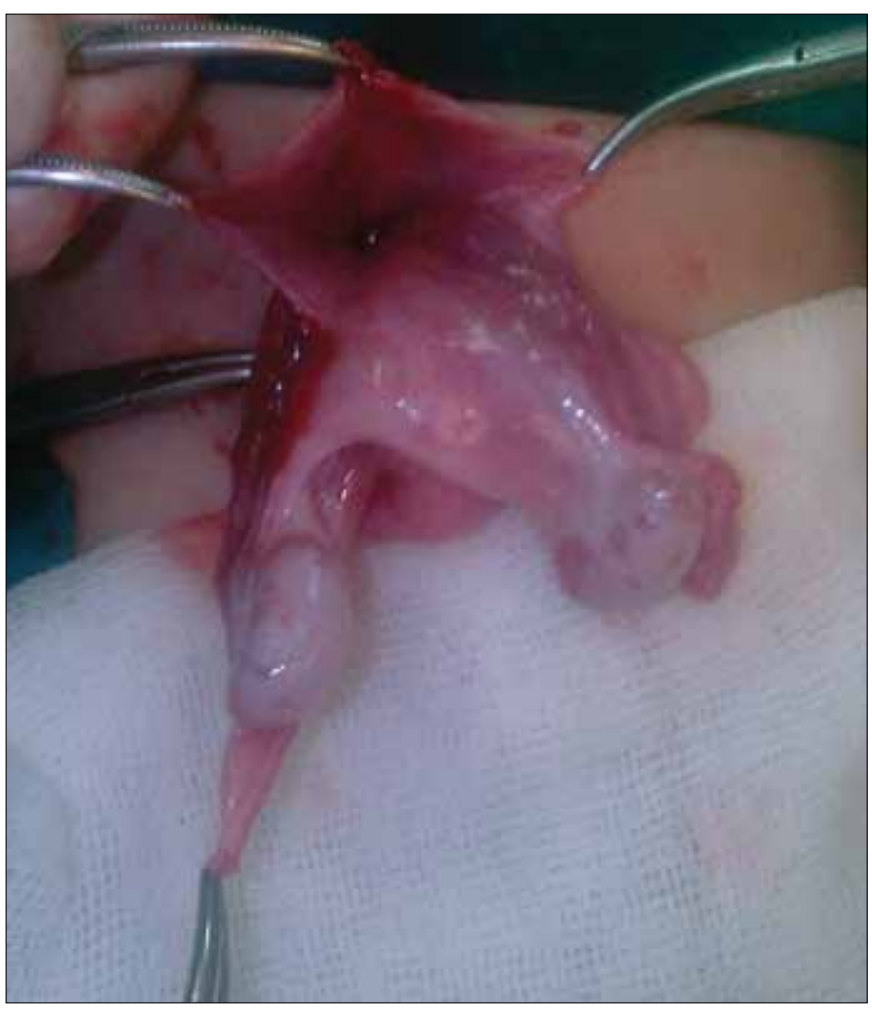

Figure 3. Intraoperative view of the right groin showing both testes with common hernia sac

testis in the inguinal canal in all of our patients. MRI and laparoscopy are useful for patients with persistent Müllerian duct syndrome $(8,9)$. Laparoscopy may be useful both to confirm the diagnosis and to perform the treatment (10). Inguinal hernia is present in $40-50 \%$ of patients. The most important diagnostic criterion is getting suspicious of TTE in patients with one side inguinal hernia and contralateral nonpalpable testis. We detected the nonpalpable testis in the contralateral inguinal region in two of our patients on clinical examination. Careful physical examination and the use of diagnostic modalities, especially ultrasonography, reduce the age of our patients with TTE.

Treatment is decided according to the presentation and associated anomalies of the patients. Orchiectomy, orchiopexy and, if present, excision of the Müllerian remnants are the treatment options (9). We performed transseptal orchiopexy since there was no damage to the ectopic testes and no associated anomalies other than inguinal hernia. Patients should be followed for long terms in case of a malignity (4).

\section{Conclusion}

Eventually it is essential to perform US scan in patients with nonpalpaple undescended testes; but the most important point is to be aware of this rare malformation and be suspicious of patients with such a clinical presentation.

\section{Conflict of Interest}

No conflict of interest was declared by the authors. 


\section{References}

1. Martin EL, Bennett AH, Cromie WJ. Persistent müllerian duct syndrome with transverse testicular ectopia and spermatogenesis. J Urol 1992;147:1615-7.

2. Chen KC, Chu CC, Chou TY. Transverse testicular ectopia: preoperative diagnosis by ultrasonography. Pediatr Surg Int 2000;16:77-9. [CrossRef]

3. Divarcı E, Ulman I, Avanoglu A. Transverse testicular ectopia treated by transseptal contralateral transposition: case report. Eur J Pediatr Surg 2011;21:191-2. [CrossRef]

4. Berkmen F. Persistent müllerian duct syndrome with or without transverse testicular ectopia and testis tumours. Br J Urol 1997;79:122-6. [CrossRef]

5. Gauderer MW, Grisoni ER, Stellato TA, Ponsky JL, Izant RJ Jr. Transverse testicular ectopia. J Pediatr Surg 1982;17:43-7. [CrossRef]
6. Frey $\mathrm{HL}$, Rajfer J. Role of the gubernaculum and intraabdominal pressure in the process of testicular descent. J Urol 1984;131:574-9.

7. Feizzadeh Kerigh B, Mohamadzadeh Rezaei M. Crossed testicular ectopia: a case report. Urol J 2005;2: 222-3.

8. Dòmini M, Gargano T, Ruggeri G, Gentili A, Manuele R, Lima M. Transverse testicular ectopia and persistent Müllerian duct syndrome: video-assisted treatment Eur J Pediatr Surg 2010;20:53-4. [CrossRef]

9. MacDonald MF, Barthold JS, Kass EJ. Abnormalities of the penis and scrotum. In: Docimo SG. The Kelalis-King-Belman Textbook of Clinical Pediatric Urology. 5th ed. London: Informa Health Care; 2007;1239-70.

10. Gornall PG, Pender DJ. Crossed testicular ectopia detected by laparoscopy. Br J Urol 1987;59:283. [CrossRef] 